\title{
“Qingfei Paidu Decoction"-A Possible Choice of Phytotherapy for Severe Acute Respiratory Infection Caused by Coronavirus Disease-19
}

\author{
Hualiang Chen*, Dandan Song, Tianlai Gao, Jingjing Yang, Yutao Ma, Qian Deng \\ Department of Pharmacy, Shaoxing Seventh People's Hospital, Shaoxing, China \\ Email: *chenxianzhi@tom.com, *chenxianzhi2000@aliyun.com
}

How to cite this paper: Chen, H.L., Song, D.D., Gao, T.L., Yang, J.J., Ma, Y.T. and Deng, Q. (2020) "Qingfei Paidu Decoction"-A Possible Choice of Phytotherapy for Severe Acute Respiratory Infection Caused by Coronavirus Disease-19. American Journal of Plant Sciences, 11, 1111-1136. https://doi.org/10.4236/ajps.2020.117079

Received: June 12, 2020

Accepted: July 21, 2020

Published: July 24, 2020

Copyright () 2020 by author(s) and Scientific Research Publishing Inc. This work is licensed under the Creative Commons Attribution International License (CC BY 4.0).

http://creativecommons.org/licenses/by/4.0/

(c) (i) Open Access

\begin{abstract}
This work is aimed to study the therapeutics and pharmacology of the treatment of severe acute respiratory infection caused by coronavirus disease-19 (COVID-19) with traditional Chinese medicine (TCM) "Qingfei Paidu Decoction". We analyze the "Diagnosis and Treatment Protocol for Novel Coronavirus Pneumonia" (Version I to Version VII) made by China, "Clinical management of severe acute respiratory infection when novel coronavirus (2019-nCoV) infection is suspected-Interim guidance" made by World Health Organization (WHO), "Therapeutic Guidelines: Respiratory" published by Australia, and the origin of classical prescription of Qingfei Paidu Decoction: "Shanghan Lun (Treatise on Febrile Diseases)" and "Jinkui Yaolue (Synopsis of Golden Chamber)". We search the dictionary of traditional Chinese medicine (Version II) manually. We search literatures from 2001 to 2020 on Wiley online library. We conduct a comparative study on the therapeutic options and indications among Qingfei Paidu Decoction, COVID-19 and chronic obstructive pulmonary disease (COPD). And we carry out pharmacological inquiry of Qingfei Paidu Decoction. The therapeutic options and indications of Qingfei Paidu Decoction in China, COVID-19 and COPD are considered to be basically consistent. Qingfei Paidu Decoction has a definite therapeutic effect on the symptoms, basic diseases and complications for COVID-19 and COPD. Qingfei Paidu Decoction is a possible choice of phytotherapy for severe acute respiratory infection caused by COVID-19.
\end{abstract}

\section{Keywords}

Qingfei Paidu Decoction, COVID-19, COPD, Pharmacology, Therapeutics

\section{Introduction}

COVID-19 has caused catastrophic damage to the global economy, politics and 
lives. More than 5 million people have been diagnosed with COVID-19.

Qingfei Paidu Decoction is one of the Chinese therapeutic options for the treatment of severe acute respiratory infections caused by COVID-19, and is one of the most highly recommend phytotherapy in China.

We attempt to explain the possible value of Qingfei Paidu Decoction in the epidemic in a way that can be understood. It is a new attempt, although the article includes comparative studies and review. We try to explain the difficult ancient texts of TCM in popular language. We try to split the classic prescription of Zhang Zhongjing's "Shanghan Lun (Treatise on Febrile Diseases)" to explain the source of Qingfei Paidu Decoction, although this may not be very appropriate. We try to compare TCM symptoms with clinical manifestations and classification of treatment guidelines, although this is not one-to-one correspondence. We try to compare the analysis of pathogenesis in classic prescription with the diagnostic assessment in diseases of therapeutic guidelines, although there still have differences. We try to compare common pharmacological effects of a group of TCM through inquiry of pharmacology with treatment options corresponding to the guideline, although the pharmacological differences exist between single chemical composition and mixed decoction. However, we try our best to expound the effectiveness and scientific nature of Qingfei Paidu Decoction. We hope this paper can bring some help to the treatment of COVID-19.

\section{Materials and Methods}

\subsection{Materials}

Research refers to analysis the "Diagnosis and Treatment Protocol for Novel Coronavirus Pneumonia" (Version I to Version VII) made by China, "Clinical management of severe acute respiratory infection when 2019-nCoV infection is suspected - Interim guidance" made by WHO, and "Therapeutic Guidelines: Respiratory" published by Australia.

Qingfei Paidu Decoction is a classical prescription derived from "Shanghan Lun (Treatise on Febrile Diseases)" and "Jinkui Yaolue (Synopsis of Golden Chamber)". "Shanghan Lun (Treatise on Febrile Diseases)" is a reference to the photocopied edition of Baiyunge, "Zhongguo Yiyao Dacheng" which published by Jilin science and technology publishing house, edited by Fang Chunyang, and "Shanghan Lun Yandu" which is the textbook for National high education in the field of traditional Chinese medicine. According to the source of literature, it is divided into four parts: Maxing Shigan decoction, Wuling Powder, Xiaochaihu decoction and Shegan Mahuang decoction to study the formulation theory and drug composition.

The dictionary of traditional Chinese medicine (Version II) is searched manually, which is published by Shanghai science and technology publishing house and redacted by Nanjing University of Traditional Chinese Medicine. The pharmacology of prescription drugs in dictionary is confirmed and the dictionary is cited until 2001. 
A literature search from 2001 to 2020 is performed on Wiley online library (https://onlinelibrary.wiley.com/).

\subsection{Methods}

A comparative study on the therapeutic options and indications among Qingfei Paidu Decoction, COVID-19 and COPD is conducted. The retrieval results of pathological etiology, disease symptoms and therapeutics of TCM are compared with the western medicine.

Pharmacological inquiry of Qingfei Paidu Decoction is carried out. The retrieval results of the pharmacology of TCM are compared with the western medicine.

\section{Results}

\subsection{The Comparison of Symptoms Bases on TCM Herbs Prescription of Qingfei Paidu Decoction with COPD and COVID-19 (Table 1)}

Maxing Shigan decoction, Wuling Powder and Xiaochaihu decoction are derived from "Shanghan Lun (Treatise on Febrile Diseases)". Shegan Mahuang decoction originates in "Jinkui Yaolue (Synopsis of Golden Chamber)". The symptoms bases on TCM herbs prescriptions are consist with the symptoms at all stage of COPD in “Therapeutic Guidelines: Respiratory” published by Australia, and they are almost consist with "Diagnosis and Treatment Protocol for Novel Coronavirus Pneumonia (Version VII)" and "Clinical management of severe acute respiratory infection when 2019-nCoV infection is suspected-Interim guidance" made by WHO. Maxing Shigan decoction is suitable for patients with light symptoms, including fever, low fever, aversion to cold, somatalgia, retching and hiccup. Wuling Powder is used for patients with vomiting, anxiety, dysuria and light fever, who suffered the disease for a period of time. Xiaochaihu decoction is suitable for patients who had typhoid for five or six days, and whose symptoms are sometimes cold sometimes hot, oppression in chest, loss of appetite, upset, vomiting or not vomiting, abdominal pain, liver discomfort, palpitation and dysuria, low fever and cough. Xiaochaihu decoction could relieve the discomfort of gastrointestinal tract, heart and kidney caused by disease. Shegan Mahuang decoction is used for bad cough, expectoration, coughing up blood, difficulty in breathing and asthma. According to the "Shanghan Lun (Treatise on Febrile Diseases)" and "Jinkui Yaolue (Synopsis of Golden Chamber)", Qinfei Paidu Decoction is accord with the symptoms of light, moderate and severe COVID-19 patients.

\subsection{The Pharmacologic Basis of the TCM Herbs Prescription in Qingfei Paidu Decoction}

According to the literature search, it is verified that single herb of Qinfei Paidu Decoction has a clear effect on antiviral, anti-inflammatory, antibacterial, liver 
Table 1. Comparison of symptoms (syndromes) based on TCM herbs formulation with COPD symptoms, clinical classification of COVID-19 symptoms, and WHO temporary document: acute respiratory distress syndrome (ARDS).

\begin{tabular}{|c|c|c|c|}
\hline $\begin{array}{l}\text { Symptoms of Shanghanlun } \\
\text { and Jinkui Yaolue }\end{array}$ & $\begin{array}{l}\text { Treatment guidelines } \\
\text { of Australia: } \\
\text { The symptoms of COPD }\end{array}$ & $\begin{array}{l}\text { Chinese protocol related } \\
\text { clinical symptoms and } \\
\text { clinical classification }\end{array}$ & $\begin{array}{l}\text { WHO temporary document: } \\
\text { acute respiratory distress } \\
\text { syndrome (ARDS) symptoms }\end{array}$ \\
\hline
\end{tabular}

Initial manifestations

(with Mahuang Xingren

Shigao Gancao Decoction)

(after sweating):

pulse float, head and neck

strong pain, aversion to cold,

fever, mild fever, Somatalgia,

retching and hiccup, vomiting
Initial manifestations: shortness of breath, cough, repeated respiratory infection, expectoration, wheezing
Mild cases:

The clinical symptoms were mild, and no manifestations of pneumonia were found on imaging. Mild hypothermia and slight weakness
Onset: New respiratory symptoms or aggravation of existing symptoms appear within one week after the diagnosis of clinical disease
Mild cases (with Wuling Powder) (after sweating): Dysphoria, insomnia, inhibited urination, mild fever
Mild cases: symptoms are less, respiratory distress after moderate activity, repeated lung infections, no impact on daily activities. FEV1 $\approx 60 \%-80 \%$ expected value

\section{Ordinary cases:}

Symptoms such as fever and respiratory tract, and manifestations of pneumonia can be seen on imaging
Mild to moderate cases (with Xiaochaihu Decoction): Typhoid for five-six days, Taiyang disease, fever, sweating, Typhoid for five-six days, stroke, chill and fever alternation, chest tightness, nausea, vomiting, inhibited urination, slight fever, cough
Moderate cases: exacerbation of shortness of breath, shortness of breath during normal walking, restricted daily activities, cough and expectoration of sputum, acute exacerbation requiring corticosteroids. FEV1 $\approx 40 \%$ - 59\% expected value

Severe cases: shortness of breath after mild activity, severe restriction of daily activities, frequent expectoration of sputum, chronic cough, acute exacerbation requiring glucocorticoids, FEV $1<40 \%$ expected value
Underlying diseases and complications: cardiovascular disease, anxiety and depression, osteoporosis, diabetes, pulmonary hypertension or pulmonary heart disease, fatigue
Severe cases: Adults who conform to any of the following criteria: 1) Onset of shortness of breath, RRN30 times/min; 2) In resting state, oxygen saturation $<93 \%$;

3) Arterial partial pressure of oxygen $\left(\mathrm{PaO}_{2}\right) /$ fraction of inspired oxygen $\left(\mathrm{FiO}_{2}\right)<300$ $\mathrm{mmHg}(1 \mathrm{mmHg}=0.133 \mathrm{kPa})$ Cases with chest imaging that shows obvious lesion progression within 24 - 48 hours > 50\% shall be managed as severe

Critical cases:

1) Respiratory fairure and requiring mechanical ventilation; 2) Shock;

3) With other organ failure that requires ICU care
Worse: Chest imaging: Bilateral pulmonary turbidity, which cannot be fully explained by pulmonary effusion, lobar or pulmonary atrophy, or pulmonary nodules. Cause of edema: respiratory failure, which cannot be fully explained by heart failure or fluid overload. If there are no risk factors, an objective assessment (e.g. echocardiography) should be performed to exclude hydrostatic pressure edema

Degree of oxygenation (adult): Mild ARDS: $200 \mathrm{mmHg}<\mathrm{PaO}_{2} / \mathrm{FiO}_{2} \leq$ $300 \mathrm{mmHg}$ (PEEP or CPAP $\geq 5 \mathrm{~cm} \mathrm{H}_{2} \mathrm{O}$ or nonmechanical ventilation)

Moderate ARDS:

$100 \mathrm{mmHg}<\mathrm{PaO}_{2} / \mathrm{FiO}_{2} \leq$ $200 \mathrm{mmHg}$ (PEEP $\geq 5 \mathrm{~cm} \mathrm{H}_{2} \mathrm{O}$ or nonmechanical ventilation)

Severe ARDS:

$\mathrm{PaO}_{2} / \mathrm{FiO}_{2} \leq 100 \mathrm{mmHg}$ (PEEP $\geq 5 \mathrm{~cm} \mathrm{H}_{2} \mathrm{O}$ or nonmechanical ventilation) 
Note: The symptoms and prescriptions described in TCM classics "Treatise on Febrile diseases" and "Synopsis of the Golden Chamber" have obvious correspondence with the clinical classification of COPD and Chinese protocol related clinical symptoms, which can also be compared with WHO temporary document: acute respiratory distress syndrome (ARDS).

protection, gastrointestinal protection, immune activity, relief of cough, expectorant and bronchiectasis. Traditional Chinese medicines such as Chaihu (Radix Bupleuri), Gan Cao (Radix Glycyrrhizae), Huangqin (Radix Scutellariae), Fuling (Poria Cocos), Huoxiang (Herba Pogostemonis), Shegan (Rhizoma Belamcandae) have been shown to have strong anti-HCoV-229E activity, anti-human immunodeficiency virus, anti-hepatitis $\mathrm{C}$ virus, significant anti-inflammatory and antibacterial effects.

\subsubsection{The Functions and Pharmacologic Basis of the Herbs of Maxing Shigan Decoction (Table 2)}

Maxing Shigan decoction is consisted of Mahuang (Herba Ephedrae), Gan Cao (Radix Glycyrrhizae), Xingren (Semen Armeniacae Amarum), and Shengshigao (Gypsum Fibrosum).

Mahuang (Herba Ephedrae) Ephedra plant species contain biologically related alkaloids including ephedrine, methylephedrine, norpseudoephedrine, pseudoephedrine, norpseudoephedrine. They have parasympathetic activity [1]. Ephedrine increases heart rate, glucose, and insulin concentrations without affecting systolic blood pressure [2]. Plant-based stimulants have similar disposition characteristics to drugs and can produce a significant cardiovascular response after a single dose [3]. Herbal ephedra can increase heart rate and blood pressure [4]. Ephedrine has indirect and direct effects on $\alpha 1, \beta 1$, and $\beta 2$ adrenergic receptors, resulting in cardiovascular effects. And it also interacts with $\beta 3$ adrenergic receptors to promote thermogenesis [5]. The effect of ephedra and Xingren (Semen Armeniacae Amarum) on relieving asthma, relieving cough and eliminating phlegm is better than that of single use [6]. Phenylpropanolamine which is the stereoisomer of norpseudoephedrine has the effects of adrenalin, relieving asthma, expectorant, antitussive, sweating, diuretic, anti-inflammatory, antipyretic, antiallergic, and improving renal function [7]. Pseudoephedrine has been used as over-the-counter anti-cold drug and flu drug for more than 50 years as an oral decongestant [8] [9].

Gan Cao (Radix Glycyrrhizae) Gan Cao (Radix Glycyrrhizae), including glycyrrhizin, $18 \beta$-glycyrrhetinic acid, glycyrrhizin $\mathrm{A}$ and $\mathrm{B}$, and isoflavones, is with a wide range of biological activities. It has been shown to have a variety of pharmacological properties, including anti-inflammatory, antiviral, antibacterial, antioxidant, anti-diabetic, antitussive, antiasthmatic and anti-cancer activities, as well as immune regulation, gastric protection, liver protection, nerve protection 
Table 2. The functions and pharmacologic basis of the herbs of Maxing Shigan decoction.

\begin{tabular}{|c|c|c|c|c|c|c|c|c|c|c|c|}
\hline Herbs & 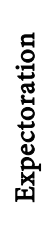 & 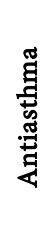 & 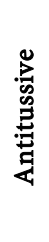 & 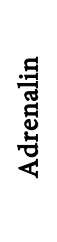 & 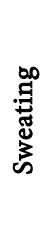 & 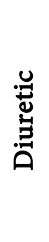 & 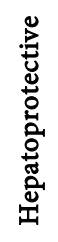 & 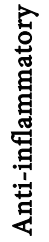 & 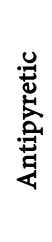 & 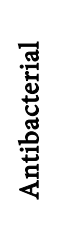 & 呇 \\
\hline $\begin{array}{c}\text { Mahuang } \\
\text { (Herba Ephedrae) }\end{array}$ & & + & + & + & + & + & & + & + & & \\
\hline $\begin{array}{c}\text { Gan Cao } \\
\text { (Radix Glycyrrhizae) }\end{array}$ & + & & + & + & & & ++ & + & & + & ++ \\
\hline $\begin{array}{c}\text { Xingren } \\
(\text { Semen Armeniacae Amarum })\end{array}$ & & + & + & & & & & + & & & \\
\hline $\begin{array}{c}\text { Shengshigao } \\
\text { (Gypsum Fibrosum) }\end{array}$ & & & & & & & & & + & & \\
\hline
\end{tabular}

\begin{tabular}{|c|c|c|c|c|c|c|c|c|c|}
\hline Herbs & 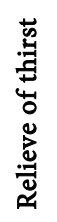 & 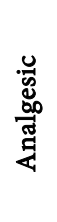 & 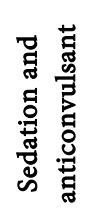 & 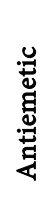 & 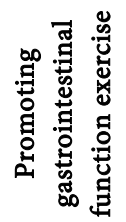 & 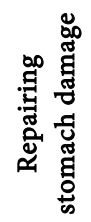 & 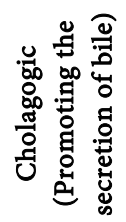 & 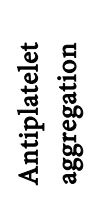 & 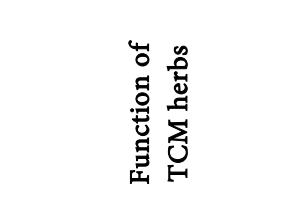 \\
\hline $\begin{array}{c}\text { Mahuang } \\
\text { (Herba Ephedrae) }\end{array}$ & & & & & & & & & $\begin{array}{l}\text { Releasing exterior by } \\
\text { diaphoresis, relieving } \\
\text { asthma with ventilating } \\
\text { lung, inducing dieresis } \\
\text { for removing edema }\end{array}$ \\
\hline $\begin{array}{c}\text { Gan Cao } \\
\text { (Radix Glycyrrhizae) }\end{array}$ & & & + & + & + & + & + & + & $\begin{array}{l}\text { Embellishing lung and } \\
\text { antidote, harmonicing } \\
\text { the property of herbs }\end{array}$ \\
\hline $\begin{array}{c}\text { Xingren } \\
\text { (Semen Armeniacae Amarum) }\end{array}$ & & + & & & + & & & & $\begin{array}{l}\text { Direct qi downward } \\
\text { to resolve phlegm, } \\
\text { relieving cough and } \\
\text { asthma, embellishing } \\
\text { aperient bowel }\end{array}$ \\
\hline $\begin{array}{c}\text { Shengshigao } \\
\text { (Gypsum Fibrosum) }\end{array}$ & + & + & & & + & & & & $\begin{array}{l}\text { Clearing away heat } \\
\text { and reducing fire, } \\
\text { antidipticum by } \\
\text { eliminating restlessness }\end{array}$ \\
\hline
\end{tabular}

and heart protection. Gan Cao (Radix Glycyrrhizae) contains a variety of chemical components, such as triterpene saponins, flavonoids, isoflavones, chalcones, and glycyrrhizic acid. Glycyrrhizic acid is considered to be the prominent active ingredient [10] [11] [12]. Triterpene glycyrrhizic acid reveals strong anti-herpes simplex virus type 1 (HSV1) activity [13]. Isoliquiritigenin (ISL) plays a dual role in regulating gastrointestinal movement, which has both spasmodic and antispasmodic effects [14]. Licorice has been confirmed that has therapeutic effect on liver diseases [15] [16] [17]. Licorice derivatives of compound glycyrrhizin and its derivatives reduces the hepatocellular injury due to chronic hepatitis $\mathrm{B}$ 
and C [17] [18], and it has the antiviral activity of herpes simplex virus (HSV), the influenza virus, human immunodeficiency virus-1 (HIV-1), severe acute respiratory syndrome (SARS) associated coronavirus, respiratory syncytial virus, arboviruses, vaccinia virus and vesicular stomatitis virus [13] [18] [19]. Besides, glycyrrhizin can ameliorate early renal dysfunction in ischemic acute renal failure [20]. Isoliquiritigenin and liquiritigenin (LTG) has significant activity against methicillin-resistant staphylococcus aureus (MRSA) [21].

Xingren (Semen Armeniacae Amarum) It has antitussive, antiphlogistic, analgesic and laxative effects.

Shengshigao (Gypsum Fibrosum) It has antipyretic, anti-inflammatory [22], thirst-quenching and analgesic effects.

\subsubsection{The Functions and Pharmacologic Basis of the Herbs of Wuling Powder (Table 3)}

Wuling Powder is composed of Guizhi (Ramulus Cinnamomi), Zexie (Rhizoma Alismatis), Zhuling (Polyporus Umbellatus), Baizhu (Rhizoma Atractylodis Macrocephalae) and Fuling (Poria Cocos).

Guizhi (Ramulus Cinnamomi) It contains a variety of components, including volatile oil, organic acids, triterpenoid saponins, coumarins, tannins, flavonoids, flavonoid glycosides, steroids and polysaccharides., which has a broad pharmacological activities, including antimicrobial activity, anti-inflammatory activity, antipyretic and analgesic activity, antiviral activity, antitumor activity, anti-diabetic activity, neuroprotective activity, antiplatelet aggregation activity and immunomodulatory activity. Among them, the main function of Guizhi are antibacterial activity, antipyretic and analgesic activity, anti-inflammatory activity and antiviral activity [23] [24]. Cinnamic acid is verified that has protective effect on endotoxin poisoned mice [25].

Zexie (Rhizoma Alismatis) The main chemical compounds of Zexie (Rhizoma Alismatis) are triterpenoids, sesquiterpenoids and diterpenoids. Prosteranes triterpenes, called alisols, possess a range of pharmacological effects, including diuretic, antimetabolic disorder, hepatoprotection, immuneregulation, antiosteoporosis, anti-inflammatory, antitumor, antibacterial and antiviral activities [26], anti-hyperlipidemia [27], and vascular activities [28] [29].

Zhuling (Polyporus Umbellatus) Study has shown that Zhuling (Polyporus Umbellatus) has diuresis, hepatoprotection, anticancer, gastric repair, promoting immune function [30]. The chemical composition of Zhuling (Polyporus Umbellatus) mainly includes polysaccharides, steroids, proteins and so on [31]. Polyporus polysaccharide mainly plays the role of immune regulation, which can act on a variety of immune cells and regulate the immune function of the body [32]. Zhuling (Polyporus Umbellatus) has significant diuretic activity, reduces angiotensin II, aldosterone, vasopressin levels, to provide certain scientific basis for the role of traditional water moisture penetration effect and multiple targets [33]. The traditional water moisture penetration effect has good pharmacological activity on renal function decline disease [34]. 
Table 3. The functions and pharmacologic basis of the herbs of Wuling powder.

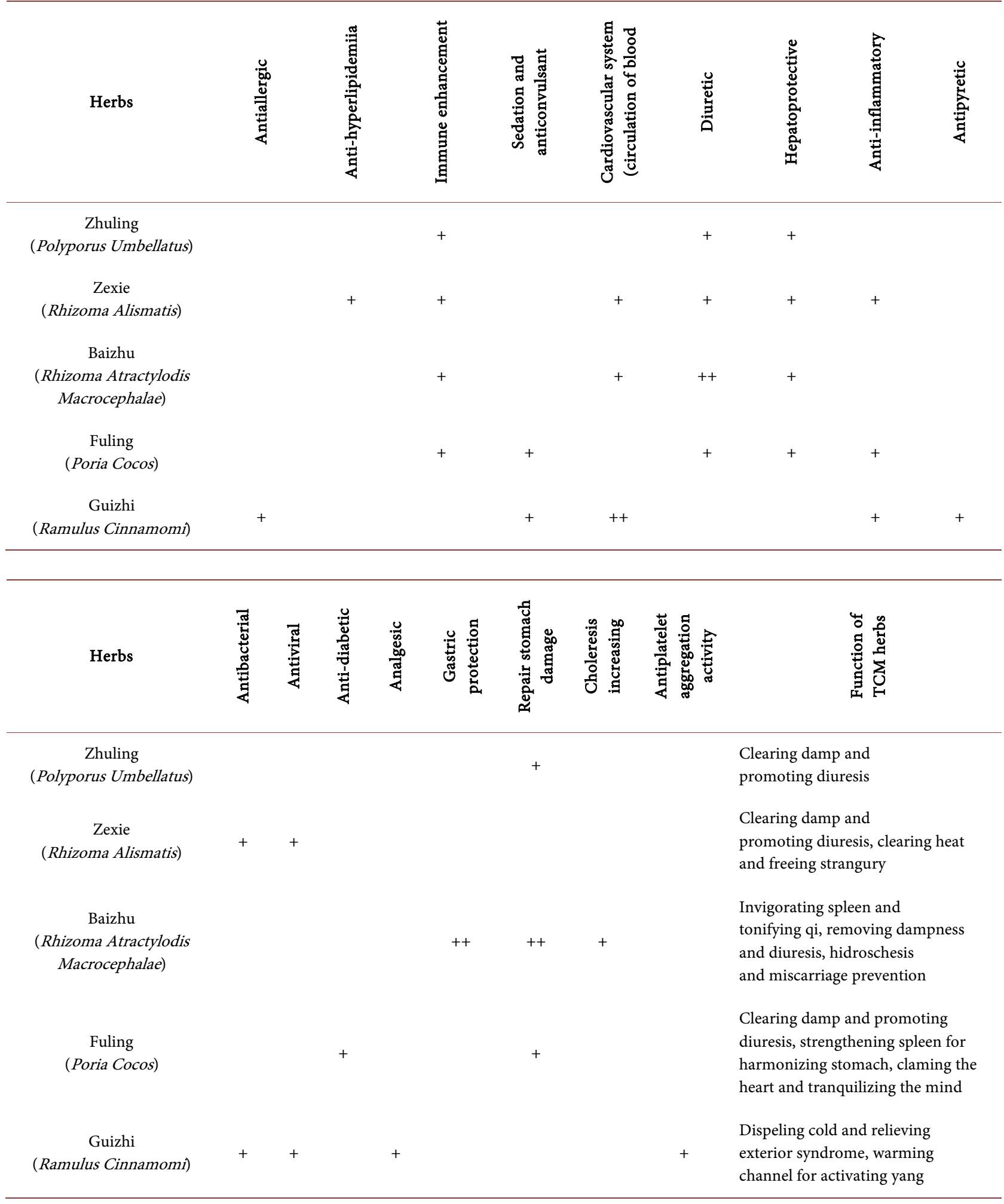

Baizhu (Rhizoma Atractylodis Macrocephalae) It contains a variety of sesquiterpenoids including atractylon, atracylenolies I, II, III and biatractylolide, and possess functions of promoting gastrointestinal movement and gastric ulcer 
repair [35], hepatoprotection, anti-oxidation, anti-aging, hypoglycemic, diuretic, resistance to ascites and increasing the immune system activity. Tractylolide that isolated from rhizoma atractylodis have been reported to have anti-inflammatory activity, inhibition of tumor necrosis factor- $\alpha$ (TNF- $\alpha$ ) activity [36] [37], cardioprotection effect and neuroprotective effect [38].

Fuling (Poria Cocos) It has anti-metastasis, anti-cancer [39] [40] [41], immune regulation, anti-diabetes [42], hepatoprotection [43], anti-inflammatory effect [40].

\subsubsection{The Functions and Pharmacologic Basis of the Herbs of Xiaochaihu Decoction (Table 4)}

"Xiaochaihu decoction" is mainly composed of Chaihu (Radix Bupleuri), Huangqin (Radix Scutellariae), Banxia (Rhizoma Pinelliae), Gan Cao (Radix Glycyrrhizae), Shengjiang (Rhizoma Zingiberis Recens), and it has antidepressant effect [44].

Chaihu (Radix Bupleuri) Taiwanese scholars demonstrate that Chaihu has anti-HCoV-229E activity. It can resist against human immunodeficiency virus, hepatitis $\mathrm{C}$ virus, measles virus, influenza virus, herpes simplex virus, Varicella zoster virus. Especially Radix Stellaviea $\mathrm{B}_{2}$, has powerful anti-HCoV-229E, anti-human immunodeficiency virus, anti-hepatitis $\mathrm{C}$ activity in low concentrations [45]. It has significant anti-inflammatory effect, and it can protect liver and immune regulatory activity, it also has antibacterial effect.

Huangqin (Radix Scutellariae) It has protective action on liver [46] [47]. Wogonin can protect against acute lung injury [48] [49] [50] [51], and it has nervous system protective effect [52] [53], gastrointestinal function protetive effect [54], anti-inflammatory effect [46] [50], anti-oxidation effect, and it can remove hydroxyl free radicals [55]. It also has obvious inhibition on smooth muscle cells. In addition, it can inhibit angiotensin converting enzyme 1 and angiotensin converting enzyme inhibition 3 [25], and treat atherosclerosis and thrombosis [56] [57]. Baicalein can protect from the whole cerebral ischemia [58], and has heart protective effect [59] [60] [61]. It also can protect cells from damage [62] [63]. In addition, Baicalein can get through the blood-brain barrier and distribute in a wide range in the areas of brain, carrying out hepatobiliary excretion [64]. Wogonin has strong anti-HBV and antibacterial or antifungal activity [50] [65]. Wogonin can also protect mice from fatal shock [66].

Banxia (Rhizoma Pinelliae) It has the functions of anti-vomiting, urging emetic, anti-cough, anti-arrhythmia and anti-experimental gastric ulcer [67] [68].

Gan Cao (Radix Glycyrrhizae) (3.2.1)

Shengjiang (Rhizoma Zingiberis Recens) It can promote the protection of gastric mucosa and gastrointestinal peristalsis, combat motion sickness, and has antiemetic effect. It can also protect liver and bile. Besides, it has sedative and anti-convulsive effect, antioxidant effect, anti-microbial effect, antipyretic and analgesic effect, anti-inflammatory effect, and it has cardiovascular activity. 
Table 4. The pharmacologic basis of the herbs of Xiaochaihu decoction.

\begin{tabular}{|c|c|c|c|c|c|c|c|c|c|c|}
\hline Herbs & 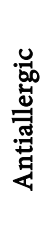 & 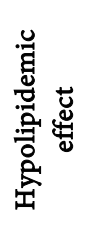 & 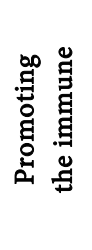 & 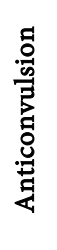 & 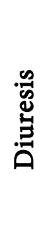 & 芯苟 & 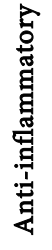 & 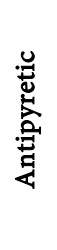 & 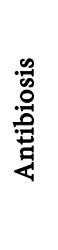 & 营 \\
\hline $\begin{array}{c}\text { Chaihu } \\
\text { (Radix Bupleuri) }\end{array}$ & & + & + & ++ & & + & ++ & ++ & + & +++ \\
\hline $\begin{array}{c}\text { Huangqin } \\
\text { (Radix Scutellariae) }\end{array}$ & & + & + & & + & + & + & & ++ & ++ \\
\hline \multicolumn{11}{|l|}{$\begin{array}{c}\text { Banxia } \\
\text { (Rhizoma Pinelliae) }\end{array}$} \\
\hline $\begin{array}{c}\text { Gan Cao } \\
\text { (Radix Glycyrrhizae) }\end{array}$ & & & & + & & ++ & + & & + & + \\
\hline $\begin{array}{c}\text { Shengjiang } \\
\text { (Rhizoma Zingiberis Recens) }\end{array}$ & & & & + & & + & + & + & + & \\
\hline
\end{tabular}

Note: According to Zhang Zhongjing's Chinese prescription, Renshen (Radix et Rhizoma Ginseng) and Dazao (Fructus Jujubae) are not used when coughing.

\begin{tabular}{|c|c|c|c|c|c|c|c|c|c|c|c|}
\hline Herbs & 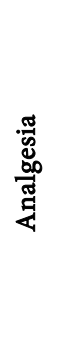 & 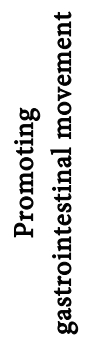 & 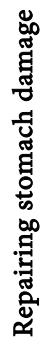 & 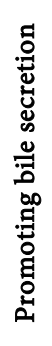 & 岕 & 莺 & 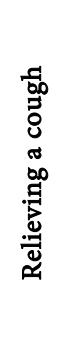 & 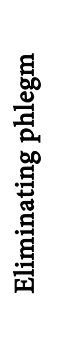 & 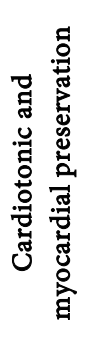 & 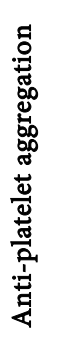 & 湺营 \\
\hline $\begin{array}{c}\text { Chaihu } \\
\text { (Radix Bupleuri) }\end{array}$ & ++ & & + & & + & & ++ & & & & $\begin{array}{l}\text { Evacuation and defervescence, } \\
\text { disperse stagnated liver } \\
\text { qi to relieve depression, } \\
\text { and lifting Yang Qi }\end{array}$ \\
\hline $\begin{array}{c}\text { Huangqin } \\
\text { (Radix Scutellariae) }\end{array}$ & & & + & & + & & & & + & + & $\begin{array}{l}\text { Heat-clearing and } \\
\text { damp-drying, purging fire } \\
\text { for removing toxin, hemostasis } \\
\text { and miscarriage prevention }\end{array}$ \\
\hline $\begin{array}{c}\text { Banxia } \\
\text { (Rhizoma Pinelliae) }\end{array}$ & & & + & & & + & +++ & & + & & $\begin{array}{l}\text { Eliminating dampness and } \\
\text { eliminating phlegm, reducing } \\
\text { adverse reactions and stopping } \\
\text { vomiting, eliminating swelling } \\
\text { and dispersing mass }\end{array}$ \\
\hline $\begin{array}{c}\text { Gan Cao } \\
\text { (Radix Glycyrrhizae) }\end{array}$ & & + & + & + & + & + & + & + & & + & $\begin{array}{l}\text { Moisten lung and } \\
\text { detoxify, harmonizing } \\
\text { various medicines }\end{array}$ \\
\hline $\begin{array}{c}\text { Shengjiang } \\
\text { (Rhizoma Zingiberis Recens) }\end{array}$ & + & + & + & + & & + & & & + & + & $\begin{array}{l}\text { Relieving exterior and dispersing } \\
\text { cold, warming middle energizer } \\
\text { to arrest vomiting, resolving } \\
\text { phlegm and relieving cough, } \\
\text { detoxify fish and crab poison }\end{array}$ \\
\hline
\end{tabular}

Note: According to Zhang Zhongjing's Chinese prescription, Renshen (Radix et Rhizoma Ginseng) and Dazao (Fructus Jujubae) are not used when coughing. 


\subsubsection{The Functions and Pharmacologic Basis of the Herbs of Shegan Mahuang Decoction (Table 5)}

"Shegan Mahuang decoction" is mainly composed of Shegan (Rhizoma Belamcandae), Mahuang (Herba Ephedrae), Shengjiang (Rhizoma Zingiberis Recens), Xixin (Radix et Rhizoma Asari), Ziwan (Radix et Rhizoma Asteris), kuandonghua (Flos Farfarae) and Banxia (Rhizoma Pinelliae).

Shegan (Rhizoma Belamcandae) It contains Belamcandin, Tectoridin, Shekanin, etc. It has the remarkable anti-inflammatory, anti-allergic, expectorant, antipyretic and analgesic effects. Shegan has a strong inhibitory effect on common pathogenic fungi. It also has inhibitory effect on certain viruses of external and laryngeal disorders (adenovirus, ECHO11). Besides, there are obvious diuretic effects. Tectoridin and tectorigenin are anti-inflammatory substance base of Shegan (Rhizoma Belamcandae) [69]. The incubation period of cough is significantly prolonged and is positively correlated after using the water extract. The cough latency of mice is significantly prolonged after combined with the mixture of anti-inflammatory and antibacterial substances, which is positively correlated with the dose. The times of cough decrease significantly [70].

Mahuang (Herba Ephedrae) (3.2.1)

Shengjiang (Rhizoma Zingiberis Recens) (3.2.3)

Xixin (Radix et Rhizoma Asari) It has functions of antipyretic, analgesic, sedative' antibacterial, anti-inflammatory, antiallergic, antispasmodic and local anesthesia. The Higenamine which Xixin includes has the effects of strengthening heart, dilating blood vessels, relaxing smooth muscle, enhancing lipid metabolism and raising blood sugar.

Ziwan (Radix et Rhizoma Asteris) It has expectorant, relief of cough, inhibit bacteria, antiviral, anticancer, hemolysis and diuretic effect.

Kuandonghua (Flos Farfarae) It has the antitussive, expectorant [71], and relieving asthma, breathing excitement, contraction of smooth muscle, contraction of blood vessels, slow heart rate, blocking calcium channel function. And It is carcinogenic. The animal tests proof that Kuandonghua has the strong antitussive effect. Water decoction can increase the respiratory secretions and make expectoration easy.

Jangbanxia (Pinelliae Rhizoma Praeparatum) It with impact of Anti-emetic, urging emetic, anti-cough, expectorant [72], anti-cancer, anti-fertility, anti-early pregnancy, anti-arrhythmia, anti-experimental ulcer, anti-silicosis, promoting peripheral lymphocyte division, etc.

Shanyao (Rhizoma Dioscoreae) It can Stimulate intestinal movement, promote gastrointestinal emptying, enhance cellular and humoral immunity. In the view of the effect of regulating blood sugar level is significantly, it can prevent and treat diabetes to some extent. Moreover, it also can obviously resist the rise of blood sugar caused by epinephrine and glucose.

Chenpi (Pericarpium Citri reticulatae) The inhibition of the gastrointestinal movement is directly. It can enhance cardiac contractile force, increases cardiac output, dilate the coronary arteries, increase coronary flow, elevate blood pressure. 
Table 5. The pharmacologic basis of the herbs of Shegan Mahuang decoction.

\begin{tabular}{|c|c|c|c|c|c|c|c|c|c|}
\hline Herbs & $\begin{array}{l}\text { Relieving } \\
\text { a cough }\end{array}$ & $\begin{array}{l}\text { Eliminate } \\
\text { phlegm }\end{array}$ & $\begin{array}{l}\text { Relieving } \\
\text { asthma }\end{array}$ & Analgesia & Antipyretic & Anti-inflammatory & Antibiosis & Antiviral & Diuresis \\
\hline $\begin{array}{c}\text { Shegan } \\
\text { (Rhizoma Belamcandae) }\end{array}$ & + & + & + & & & + & + & & + \\
\hline $\begin{array}{c}\text { Mahuang } \\
\text { (Herba Ephedrae) }\end{array}$ & + & & + & & + & + & & & + \\
\hline $\begin{array}{c}\text { Shengjiang } \\
\text { (Rhizoma Zingiberis Recens) }\end{array}$ & & & & + & + & + & + & & \\
\hline $\begin{array}{c}\text { Xixin } \\
\text { (Radix et Rhizoma Asari) }\end{array}$ & & & & + & + & & + & & \\
\hline $\begin{array}{c}\text { Ziwan } \\
\text { (Radix et Rhizoma Asteris) }\end{array}$ & + & + & & & & & & & \\
\hline $\begin{array}{l}\text { kuandonghua } \\
\text { (Flos Farfarae) }\end{array}$ & + & + & & & & + & & & \\
\hline $\begin{array}{c}\text { Jangbanxia } \\
\text { (Pinelliae Rhizoma } \\
\text { Praeparatum) }\end{array}$ & +++ & & & & & & & & \\
\hline $\begin{array}{c}\text { Shanyao } \\
\text { (Rhizoma Dioscoreae) }\end{array}$ & & & & & & & & & \\
\hline $\begin{array}{c}\text { Chenpi } \\
\text { (Pericarpium } \\
\text { Citri Reticulatae) }\end{array}$ & + & + & & & & + & & & \\
\hline $\begin{array}{c}\text { Huoxiang } \\
\text { (Herba Pogostemonis) }\end{array}$ & & & & & & & ++ & + & \\
\hline $\begin{array}{c}\text { Zhishi } \\
\text { (Fructus Aurantii Immaturus) }\end{array}$ & & & & & & + & + & & \\
\hline
\end{tabular}

Note: According to Zhang Zhongjing's Chinese prescription, Renshen (Radix et Rhizoma Ginseng) and Dazao (Fructus Jujubae) are not used when coughing.

\begin{tabular}{|c|c|c|c|c|c|c|c|}
\hline Herbs & $\begin{array}{c}\text { Promoting } \\
\text { gastrointestinal } \\
\text { movement }\end{array}$ & $\begin{array}{c}\text { Repairing } \\
\text { stomach } \\
\text { damage }\end{array}$ & $\begin{array}{c}\text { Liver } \\
\text { protection }\end{array}$ & $\begin{array}{l}\text { Promoting } \\
\text { bile secretion }\end{array}$ & Antiemetic & $\begin{array}{l}\text { Hypoglycemic } \\
\text { effect }\end{array}$ & $\begin{array}{c}\text { Cardiotonic } \\
\text { and myocardial } \\
\text { preservation }\end{array}$ \\
\hline Shegan (Rhizoma Belamcandae) & & + & & + & & & \\
\hline \multicolumn{8}{|l|}{ Mahuang (Herba Ephedrae) } \\
\hline $\begin{array}{c}\text { Shengjiang } \\
\text { (Rhizoma Zingiberis Recens) }\end{array}$ & + & + & & + & + & & + \\
\hline \multicolumn{8}{|l|}{ Xixin (Radix et Rhizoma Asari) } \\
\hline \multicolumn{8}{|l|}{ Ziwan (Radix et Rhizoma Asteris) } \\
\hline kuandonghua (Flos Farfarae) & & & & & & & + \\
\hline $\begin{array}{c}\text { Jangbanxia } \\
\text { (Pinelliae Rhizoma Praeparatum) }\end{array}$ & & + & & & + & & + \\
\hline Shanyao (Rhizoma Dioscoreae) & + & ++ & + & & & + & \\
\hline Chenpi (Pericarpium Citri Reticulatae) & & ++ & & & & & \\
\hline
\end{tabular}




\section{Continued}

\begin{tabular}{ccc}
\hline Huoxiang (Herba Pogostemonis) & + \\
Zhishi (Fructus Aurantii Immaturus) & ++ \\
\hline
\end{tabular}

Note: According to Zhang Zhongjing's Chinese prescription, Renshen (Radix et Rhizoma Ginseng) and Dazao (Fructus Jujubae) are not used when coughing.

\begin{tabular}{|c|c|c|c|c|c|c|c|}
\hline Herbs & $\begin{array}{l}\text { Anti-platelet } \\
\text { aggregation }\end{array}$ & $\begin{array}{l}\text { Cardiovascular } \\
\text { system (blood } \\
\text { circulation) }\end{array}$ & $\begin{array}{l}\text { Resistance to } \\
\text { nephropathy }\end{array}$ & Sweat & Antiallergic & $\begin{array}{l}\text { Promoting } \\
\text { the immune }\end{array}$ & $\begin{array}{l}\text { Function of } \\
\text { TCM herbs }\end{array}$ \\
\hline $\begin{array}{l}\text { Shegan } \\
\text { (Rhizoma } \\
\text { Belamcandae) }\end{array}$ & + & + & & + & + & & $\begin{array}{l}\text { Clearing away heat and toxic } \\
\text { materials. dissolving phlegm, } \\
\text { relieving sore-throat }\end{array}$ \\
\hline $\begin{array}{l}\text { Shengjiang } \\
\text { (Rhizoma } \\
\text { Zingiberis } \\
\text { Recens) }\end{array}$ & + & & & & & & $\begin{array}{l}\text { Relieving exterior and dispersing } \\
\text { cold, warming middle energizer } \\
\text { to arrest vomiting, resolving } \\
\text { phlegm and relieving cough, } \\
\text { detoxify fish and crab poison }\end{array}$ \\
\hline $\begin{array}{c}\text { Xixin } \\
\text { (Radix et } \\
\text { Rhizoma Asari) }\end{array}$ & & ++ & + & & & & $\begin{array}{l}\text { Expelling wind and removing } \\
\text { cold, dispelling wind and relieving } \\
\text { pain, being sensible or reasonable, } \\
\text { warm the lung and resolve fluid ret }\end{array}$ \\
\hline $\begin{array}{c}\text { Ziwan } \\
\text { (Radix et } \\
\text { Rhizoma Asteris) }\end{array}$ & & & & & & & $\begin{array}{l}\text { Moisten lung and lower Qi, } \\
\text { eliminating phlegm and } \\
\text { relieving cough }\end{array}$ \\
\hline $\begin{array}{l}\text { Kuandonghua } \\
\text { (Flos Farfarae) }\end{array}$ & & & & & & & $\begin{array}{l}\text { Moisten lung and lower Qi, } \\
\text { relieving cough and } \\
\text { resolving phlegm }\end{array}$ \\
\hline $\begin{array}{l}\text { Shanyao } \\
\text { (Rhizoma } \\
\text { Dioscoreae) }\end{array}$ & & & & & & + & $\begin{array}{l}\text { Tonifying spleen and nourishing } \\
\text { the stomach, promoting fluid and } \\
\text { benefiting lung, tonifying essence } \\
\text { and astringent essenc }\end{array}$ \\
\hline $\begin{array}{c}\text { Chenpi } \\
\text { (Pericarpium } \\
\text { Citri Reticulatae) }\end{array}$ & & + & & & & & $\begin{array}{l}\text { Regulating qi and invigorating } \\
\text { spleen, drying dampness and } \\
\text { resolving phlegm }\end{array}$ \\
\hline $\begin{array}{c}\text { Huoxiang } \\
\text { (Herba } \\
\text { Pogostemonis) }\end{array}$ & + & & & & & & $\begin{array}{l}\text { Eliminating dampness with } \\
\text { aromatics, release to relieve } \\
\text { summer heat }\end{array}$ \\
\hline $\begin{array}{c}\text { Zhishi } \\
\text { (Fructus Aurantii } \\
\text { Immaturus) }\end{array}$ & & & & + & & & $\begin{array}{l}\text { Breaking Qi and eliminating } \\
\text { accumulation, resolving phlegm } \\
\text { and dispersing swelling }\end{array}$ \\
\hline
\end{tabular}

Note: According to Zhang Zhongjing's Chinese prescription, Renshen (Radix et Rhizoma Ginseng) and Dazao (Fructus Jujubae) are not used when coughing. 
It also can inhibit the heart with high doses. The extract of Chenpi has the effect of scavenging oxygen free radicals, anti-lipid peroxidation, dilating trachea. The essential oil can make expectoration easy. The General flavone has antiallergic activity in vitro and in vivo [73].

Huoxiang (Herba Pogostemonis) It almost includes $1.5 \%$ volatile oil. It can promote the secretion of gastric juice, enhance the digestive power, and it has the antispasmodic effect on gastrointestinal tract. It also has antibacterial [74], antiviral effect. In addition, it has antidiarrheal effect, microvascular dilation effect, and slightly sweating effects.

Zhishi (Fructus Aurantii Immaturus) It includes hesperidin, neohesperidin, and naringin. It has significant promoting effect on gastrointestinal propulsive movement, and obvious anti-inflammatory effect. Its decoction has obvious hypertensive effect, anti-allergy effect, and anti-platelet aggregation effect.

\subsection{Corresponding Relationship between the Herbs of "Qingfei Paidu Decoction" and the Important Organ Symptoms of COVID-19 Disease (Table 6)}

According to pharmacological activity analysis, it is found that the traditional Chinese medicine is used in the form of compound formulae and exists in the form of functional group. Multiple drugs treat a system together, and have obvious pharmacological effects on the clinical manifestations or pathological changes of important organ of COVID-19. Our analysis found that traditional Chinese medicines with antipyretic effect include Xixin (Radix et Rhizoma Asari), Chaihu (Radix Bupleuri), Shengjiang (Rhizoma Zingiberis Recens), Mahuang (Herba Ephedrae), Shengshigao (Gypsum Fibrosum) and Guizhi (Ramulus Cinnamomi). Among the drugs that act on the respiratory system, antitussive drugs are Mahuang (Herba Ephedrae), Gan Cao (Radix Glycyrrhizae), Xingren (Semen Armeniacae Amarum), Ziwan (Radix Asteris), Kuandonghua (Flos Farfarae), Chenpi (Pericarpium Citri Reticulatae) and Chaihu (Radix Bupleuri), expectorant drugs are Shegan (Rhizoma Belamcandae), Ziwan (Radix Asteris), Kuandonghua (Flos Farfarae), Chenpi (Pericarpium Citri Reticulatae) and Gan Cao (Radix Glycyrrhizae), asthma drugs are Mahuang (Herba Ephedrae) and Xingren (Semen Armeniacae Amarum). Drugs that are active against gastrointestinal symptoms are Kuandonghua (Flos Farfarae), Shanyao (Rhizoma Dioscoreae), Chenpi (Pericarpium Citri Reticulatae), Zhishi (Fructus Aurantii Immaturus), Shengjiang (Rhizoma Zingiberis Recens), Chaihu (Radix Bupleuri), Banxia (Rhizome Pinelliae), Gan Cao (Radix Glycyrrhizae) and Baizhu (Rhizoma Atractylodis Macrocephalae). Banxia (Rhizome Pinelliae) and Shengjiang (Rhizoma Zingiberis Recens) can stop vomiting. Drugs that have a protective effect on the hepatobiliary system incude Gan Cao (Radix Glycyrrhizae), Chaihu (Radix Bupleuri), Zhuling (Polyporus Umbellatus), Zexie (Rhizoma Alismatis), Baizhu (Rhizoma Atractylodis Macrocephalae), Fuling (Poria Cocos), Huangqin (Radix Scutellariae) and Shegan (Rhizoma Belamcandae). Shengjiang (Rhizoma Zingiberis Recens), Zhuling (Polyporus Umbellatus), Zexie (Rhizoma Alismatis), 
Table 6. Corresponding relationship between Chinese herbal medicine with corresponding pharmacological effects on important organs and signs and symptoms of COVID-19.

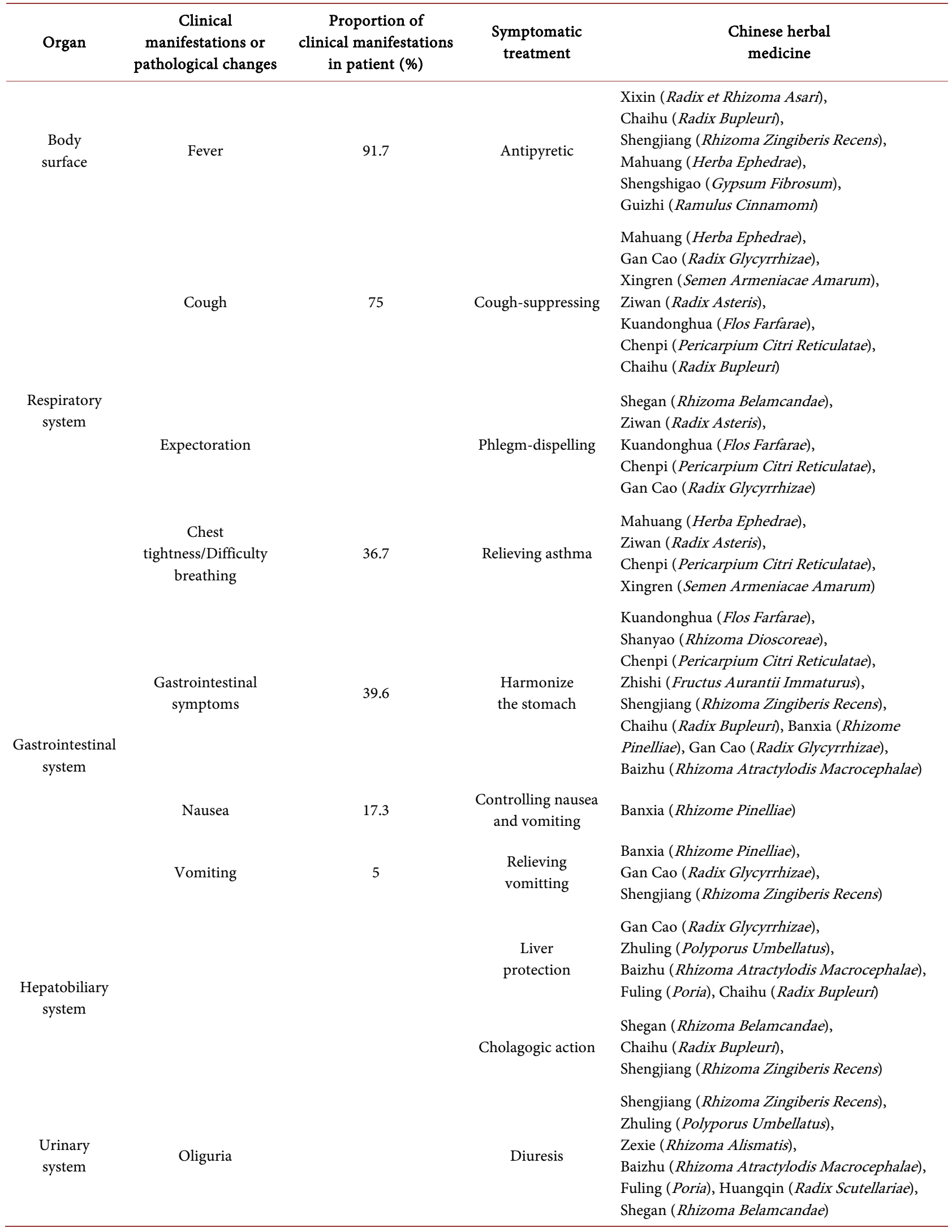




\section{Continued}

\begin{tabular}{|c|c|c|c|c|}
\hline \multirow{2}{*}{ Blood system } & & & $\begin{array}{l}\text { Anti-platelet } \\
\text { aggregation }\end{array}$ & $\begin{array}{l}\text { Huangqin (Radix Scutellariae), } \\
\text { Shegan (Rhizoma Belamcandae), } \\
\text { Xixin (Radix et Rhizoma Asari), } \\
\text { Zhishi (Fructus Aurantii Immaturus) }\end{array}$ \\
\hline & & & $\begin{array}{c}\text { Blood } \\
\text { circulation }\end{array}$ & $\begin{array}{l}\text { Zexie (Rhizoma Alismatis), } \\
\text { Baizhu (Rhizoma Atractylodis Macrocephalae), } \\
\text { Guizhi (Ramulus Cinnamomi), } \\
\text { Xixin (Radix et Rhizoma Asari) }\end{array}$ \\
\hline \multirow{4}{*}{ Heart } & Cardiopalmus & & Heart protection & $\begin{array}{l}\text { Huangqin (Radix Scutellariae), } \\
\text { Kuandonghua (Flos Farfarae) }\end{array}$ \\
\hline & & & Adrenaline effect & $\begin{array}{l}\text { Mahuang (Herba Ephedrae), } \\
\text { Mahuang (Herba Ephedrae) }\end{array}$ \\
\hline & & & Antiarrhythmia & Banxia (Rhizome Pinelliae) \\
\hline & & & Cardiotonic effect & $\begin{array}{l}\text { Shengjiang (Rhizoma Zingiberis Recens), } \\
\text { Zhishi (Fructus Aurantii Immaturus) }\end{array}$ \\
\hline \multirow{3}{*}{$\begin{array}{l}\text { Central } \\
\text { system }\end{array}$} & $\begin{array}{l}\text { Abdominal } \\
\text { pain/myalgia }\end{array}$ & 5.8 & Analgesic effect & $\begin{array}{l}\text { Xixin (Radix et Rhizoma Asari), } \\
\text { Chaihu (Radix Bupleuri), } \\
\text { Shengjiang (Rhizoma Zingiberis Recens), } \\
\text { Xingren (Semen Armeniacae Amarum), } \\
\text { Shengshigao (Gypsum Fibrosum), } \\
\text { Guizhi (Ramulus Cinnamomi) }\end{array}$ \\
\hline & Dysphoria & & Sedative effect & $\begin{array}{l}\text { Chaihu (Radix Bupleuri), } \\
\text { Shengjiang (Rhizoma Zingiberis Recens), } \\
\text { Guizhi (Ramulus Cinnamomi) }\end{array}$ \\
\hline & & & Anticonvulsant & $\begin{array}{l}\text { Xixin (Radix et Rhizoma Asari), } \\
\text { Shengjiang (Rhizoma Zingiberis Recens), } \\
\text { Guizhi (Ramulus Cinnamomi) }\end{array}$ \\
\hline
\end{tabular}

Baizhu (Rhizoma Atractylodis Macrocephalae), Fuling (Poria Cocos), Huangqin (Radix Scutellariae) and Shegan (Rhizoma Belamcandae) have a diuretic effect. For the blood system, Gan Cao (Radix Glycyrrhizae), Shengjiang (Rhizoma Zingiberis Recens), Guizhi (Ramulus Cinnamomi) and Huangqin (Radix Scutellariae) have anti-platelet aggregation effect, Baizhu (Rhizoma Atractylodis Macrocephalae), Zhishi (Fructus Aurantii Immaturus), Guizhi (Ramulus Cinnamomi), Shegan (Rhizoma Belamcandae), Huangqin (Radix Scutellariae) and Mahuang (Herba Ephedrae) have anticoagulant and antithrombotic effects. Huangqin (Radix Scutellariae) and Kuandonghua (Flos Farfarae) can protect the heart. Banxia (Rhizome Pinelliae) can resist arrhythmia. Mahuang (Herba Ephedrae) and Gan Cao (Radix Glycyrrhizae) have adrenaline effect. Shengjiang (Rhizoma Zingiberis Recens) and Zhishi (Fructus Aurantii Immaturus) have a cardiotonic effect. For the central system, Xixin (Radix et Rhizoma Asari), Chaihu (Radix Bupleuri), Shengjiang (Rhizoma Zingiberis Recens), Xingren (Semen Armeniacae Amarum), Shengshigao (Gypsum Fibrosum) and Guizhi (Ramulus Cinnamomi) have analgesic effects, Chaihu (Radix Bupleuri), Shengjiang (Rhizoma Zingiberis Recens) and Guizhi (Ramulus Cinnamomi) have a sedative effect, and Xixin (Radix et Rhizoma Asari), Shengjiang (Rhizoma Zingiberis Recens) and Guizhi 
(Ramulus Cinnamomi) have anticonvulsant effects.

\subsection{Important Laboratory Parameters of COVID-19 and Traditional Chinese Herbal Medicine Functional Groups with Clear Pharmacological Support (Table 7)}

According to the pharmacological activity analysis literature, it is found that the traditional Chinese medicine components have clear basic experimental support for important laboratory parameters of COVID-19. A variety of drugs work together in the form of functional groups, and play a pharmacologically active therapeutic role on a disease laboratory parameter.

Our analysis find that the drugs reduce persistent inflammatory response C-reactive protein (CRP) inflammatory factors are Mahuang (Herba Ephedrae), Gan Cao (Radix Glycyrrhizae), Xingren (Semen Armeniacae Amarum), Zexie (Rhizoma Alismatis), Guizhi (Ramulus Cinnamomi), Chaihu (Radix Bupleuri). Drugs that reduce secondary bacterial infections with elevated calcitonin include Chaihu (Radix Bupleuri), Gan Cao (Radix Glycyrrhizae), Guizhi (Ramulus Cinnamomi), Xixin (Radix et Rhizoma Asari), Huangqin (Radix Scutellariae), Shengjiang (Rhizoma Zingiberis Recens), Huoxiang (Herba Pogostemonis), Zhishi (Fructus Aurantii Immaturus), Shegan (Rhizoma Belamcandae). Drugs that reduce liver enzymes and lactate dehydrogenase (LDH) include Gan Cao (Radix Glycyrrhizae), Chaihu (Radix Bupleuri), Zhuling (Polyporus Umbellatus), Baizhu (Rhizoma Atractylodis Macrocephalae), and Fuling (Poria Cocos).

Table 7. Important laboratory parameters of COVID-19 and traditional Chinese herbal medicine functional groups with clear pharmacological support.

\begin{tabular}{|c|c|c|c|}
\hline $\begin{array}{c}\text { Laboratory } \\
\text { inspection parameters }\end{array}$ & Pathology & $\begin{array}{l}\text { Pharmacology } \\
\text { of Chinese } \\
\text { herbal medicine }\end{array}$ & Name of Chinese herbal medicine \\
\hline $\begin{array}{l}\mathrm{CRP} \uparrow \\
\mathrm{RCT} \uparrow \\
\mathrm{WBC} \uparrow\end{array}$ & $\begin{array}{c}\text { Persistent } \\
\text { inflammation }\end{array}$ & Anti-inflammatory & $\begin{array}{l}\text { Mahuang (Herba Ephedrae), Gan Cao (Radix Glycyrrhizae), } \\
\text { Xingren (Semen Armeniacae Amarum), } \\
\text { Zexie (Rhizoma Alismatis), Guizhi (Ramulus Cinnamomi), } \\
\text { Chaihu (Radix Bupleuri) }\end{array}$ \\
\hline Calcitonin $\uparrow$ & $\begin{array}{l}\text { Bacterial } \\
\text { infection }\end{array}$ & Antibacterial & $\begin{array}{l}\text { Chaihu (Radix Bupleuri), Gan Cao (Radix Glycyrrhizae), } \\
\text { Guizhi (Ramulus Cinnamomí), } \\
\text { Xixin (Radix et Rhizoma Asari), Mahuang (Herba Ephedrae), } \\
\text { Shengjiang (Rhizoma Zingiberis Recens), } \\
\text { Huoxiang (Herba Pogostemonis), } \\
\text { Zhishi (Fructus Aurantii Immaturus), } \\
\text { Shegan (Rhizoma Belamcandae) }\end{array}$ \\
\hline D-dimer $\uparrow$ & $\begin{array}{c}\text { Thrombotic } \\
\text { disease }\end{array}$ & Anticoagulant & $\begin{array}{l}\text { Baizhu (Rhizoma Atractylodis Macrocephalae), } \\
\text { Zhishi (Fructus Aurantii Immaturus), } \\
\text { Guizhi (Ramulus Cinnamomi), } \\
\text { Shegan (Rhizoma Belamcandae), } \\
\text { Mahuang (Herba Ephedrae), Mahuang (Herba Ephedrae) }\end{array}$ \\
\hline $\begin{array}{c}\text { Liver enzymes } \uparrow \\
\text { Lactate dehydrogenase }(\mathrm{LDH}) \uparrow\end{array}$ & $\begin{array}{c}\text { Liver } \\
\text { damage }\end{array}$ & Liver protection & $\begin{array}{l}\text { Gan Cao (Radix Glycyrrhizae), Chaihu (Radix Bupleuri), } \\
\text { Zhuling (Polyporus Umbellatus), } \\
\text { Baizhu (Rhizoma Atractylodis Macrocephalae), Fuling (Poria) }\end{array}$ \\
\hline
\end{tabular}


Baizhu (Rhizoma Atractylodis Macrocephalae), Zhishi (Fructus Aurantii Immaturus), Guizhi (Ramulus Cinnamomi), Shegan (Rhizoma Belamcandae), Huangqin (Radix Scutellariae) and Mahuang (Herba Ephedrae) can reduce D-dimer.

\section{Discussion}

The Chinese treatment protocol "Qingfei Paidu Decoction" is based on the combination of classic prescriptions in "Treatise on Febrile and Miscellaneous Diseases" and "Synopsis of Golden Chamber" written by the medical saint Zhang Zhongjing of the Han Dynasty. According to historical records, the land of China suffered from a severe plague during the first year of Eastern Han Dynasty construction to the first ten years. Due to the plague, the population of the Zhang Zhongjing's family decreased from more than 200 to 60 - 70 people, and about 100 of them died from typhoid fever. As a local official Changsha Taishou and medical scientist, Zhang Zhongjing actively organized rescue and medical treatment. During this period, "Treatise on Febrile and Miscellaneous Diseases" and "Synopsis of Golden Chamber" were born. This great work is extremely far-reaching, and it is the basic classic of traditional Chinese medicine, and Japanese Kampo Medicine is also based on this. "The Handbook of Prescriptions for Emergencies" clearly pointed out that "typhoid fever, shiqi, and plague have the same kind of characteristic". It can be seen that the so-called "typhoid fever" in "Treatise on Febrile and Miscellaneous Diseases" is the so-called "plague" in later generations.

Zhang Zhongjing's classic herbal formulae of "Mahuang Xingren Gancao Shigao decoction", "Wuling Powder", "Xiaochaihu Decoction" and "Shegan Mahuang Decoction" in "Treatise on Febrile and Miscellaneous Diseases" and "Synopsis of Golden Chamber" can be used to treat fever and cough, gastrointestinal discomfort, chest tightness, shortness of breath, palpitation and dysuria, pulmonary emphysema, lung carbuncle, expectoration and hemoptysis, difficulty breathing and other disease symptoms caused by exogenous typhoid. The above-mentioned disease symptoms, the disease progression of COPD described in the guidelines and the development process of COVID-19 pneumonia disease from light to serious have a very high similarity. The dialectical treatment process adopted by classic herbal formulae also has a high similarity to the COPD treatment protocol in the respiratory disease guidelines. From a pharmacological point of view, the pharmacological treatments adopted by the "Mahuang Xingren Gancao Shigao decoction", "Wuling Powder", "Xiaochaihu Decoction", and "Shegan Mahuang Decoction" are basically consistent with the COPD treatment protocol in the respiratory disease guidelines.

The main efficacy of the Chinese treatment protocol "Qingfei Paidu Decoction" is clear. In response to the symptoms of fever, coughing, expectoration, and dyspnea symptoms in COVID-19 pneumonia, this formula has a clear antipyretic, relieving cough, eliminating phlegm, and bronchodilator effect. The formula has obvious anti-inflammatory, anti-bacterial and anti-viral effects on the inflammatory factor exudation present in COVID-19 pneumonia. It can ob- 
viously protect the gastric mucosa, promote bile secretion, and promote gastrointestinal tract symptoms against gastrointestinal discomfort symptoms caused by COVID-19 pneumonia. It has obvious protective effect on liver damage caused by COVID-19 pneumonia virus and obvious diuretic effect on the urinary system. It promotes blood microcirculation in the blood system and is conducive to self-repair of organs. It has a significant sedative effect on the central nervous system disease. The dosage of Chinese herbal medicine in the formula is sufficient to produce the effect, and the protection of the liver also reduces the damage of other drugs to the liver.

Among community-acquired COVID-19 patients, $64.3 \%$ had comorbidities, $30 \%$ had hypertension, $12.1 \%$ had diabetes, $5.7 \%$ had fatty liver and abnormal liver function, $5.0 \%$ had coronary heart disease, $5.0 \%$ had chronic gastritis and gastric ulcer [75]. The presence of comorbidities made the disease worse. The COVID-19 virus may attack multiple organs. The harmonious treatment of multiple organs in traditional Chinese medicine helps to alleviate the disease.

Traditional Chinese medicine generally works in the form of compound prescriptions. He Ping and other authors believe that it is a functional group. The method of herbal functional groups can be found in a large number of formulae recorded in Chinese medicine books. In the study of pharmacology, it is found that in the treatment of symptoms such as cough and sputum, several drugs are often used together. In the guidelines, the treatment of respiratory diseases and cardiovascular diseases is also in the form of combination drugs. At the same time, the relationship between dosage and therapeutic effect is also concerned in combination use. A controlled study found that in different stages of the disease, traditional Chinese medicine combines herbs with the same efficacy to enhance the effectiveness of treatment and increase the synergy of treatment.

Shijun Wang and other scholars conducted a systematic study on the treatment of respiratory diseases with traditional Chinese medicine, and the article summarized the efficacy of COPD in detail [76]. The clinical treatment of COVID-19 pneumonia by traditional Chinese medicine in the Chinese protocol has also been widely recognized. Herbs in the Chinese treatment protocol "Qingfei Paidu Decoction" may have renal and hepatotoxicity, it is a big obstacle for the use of traditional Chinese medicine for medical personnel with non-traditional medical background. In particular, nephrotoxicity events caused by aristolochic acid such as Mutong (Caulis Akebiae) and Heshouwu (Multiflori Polygoni Radix) have a great impact on the use of traditional Chinese medicine. In this protocol, Xixin (Herba Asari) and Banxia (Rhizome Pinelliae) have a certain effect, but the overall drug toxicity is very low. The detoxification function of traditional Chinese medicine Gan Cao (Radix Glycyrrhizae) and the liver-protective effect of Chaihu (Radix Bupleuri), Fuling (Poria Cocos), Zhuling (Polyporus Umbellatus), Shanyao (Rhizoma Dioscoreae), Baizhu (Rhizoma Atractylodis Macrocephalae), etc. can alleviate the side effects caused by Xixin (Herba Asari) and Banxia (Rhizome Pinelliae). Traditional Chinese medicine emphasizes the detoxification of Gan Cao (Radix Glycyrrhizae) and its regulating functions of vari- 
ous medicines, which actually illustrates this effect.

Traditional Chinese medicine is based on thousands of years of history. It is an effective treatment method based on the extensive practice and use of the Chinese people in the fight against diseases. It is a scientific summary under the conditions at that time. The theory of traditional Chinese medicine is based on the yin and yang five elements theory of Chinese traditional philosophy "Zhouyi". In short, it is a universal connection and interaction theory of a simple phenomenon. Traditional Chinese medicine has made a universal connection between the etiology, symptoms, pharmacology, and medicinal properties, which is based on philosophy. After nearly 100 years of hard work, traditional Chinese medicine has obtained rich research results and made great progress in chemistry, pharmacology, experimental pharmacology, toxicology, and pharmacodynamics. Traditional Chinese medicine has the material basis. The artemisinin is extracted from the traditional Chinese herbal medicine Artemisia annua by the Chinese first Nobel Prize winner in medicine, the famous pharmacist, Ms. Tu Youyou. Baicalin in Huangqin (Radix Scutellariae), glycyrrhizic acid in Gan Cao (Radix Glycyrrhizae), ephedrine in Mahuang (Herba Ephedrae) and amygdalin in Xingren (Semen Armeniacae Amarum) all have clear material basis. In the same way, each herb in "Qingfei Paidu Decoction" has the relatively clear substance (chemical) basis and pharmacological effect. Qingfei Paidu Decoction is a possible choice to treat severe acute respiratory infection caused by COVID-19 in the case of the global epidemic crisis, and the vaccine and effective anti-COVID-19 drugs are still being studied.

\section{Conflicts of Interest}

The authors declare no conflicts of interest regarding the publication of this paper. The authors of this article have received no financial or material support from any corporation, foundation or individual.

\section{Authors' Contribution}

Hualiang Chen contributed to the conception and design of the manuscript, presided over the work and drafted most of the article. Dandan Song participated in the discussion of the conception of this article, completed the collection and wrote some chapters, completed the English translation of some chapters, made a synthesis of English translation of the whole article, revised the manuscript and corrected grammar and sentence construction. Tianlai Gao participated in the discussion of the composition of this article, completed the data collection of some chapters of traditional Chinese medicine, and wrote some theories of traditional Chinese medicine. Jingjing Yang, and Yutao Ma Participated in the discussion of the conception of this article, completed the collection of materials and wrote some chapters, and completed the English translation of some chapters. Qian Deng participated in the discussion of the conception of this article and completed the data collection and drafted some chapters of pharmacology. 


\section{References}

[1] EFSA Panel on Food Additives and Nutrient Sources added to Food (ANS) (2013) Scientific Opinion on Safety Evaluation of Ephedra Species for Use in Food. EFSA Journal, 11, 3467. https://doi.org/10.2903/j.efsa.2013.3467

[2] Haller, C.A., Jacob III, P. and Benowitz, N.L. (2004) Enhanced Stimulant and Metabolic Effects of Combined Ephedrine and Caffeine. Clinical Pharmacology \& Therapeutics, 75, 259-273. https://doi.org/10.1016/j.clpt.2003.11.375

[3] Haller, C.A., Jacob III, P. and Benowitz, N.L. (2002) Pharmacology of Ephedra Alkaloids and Caffeine after Single-Dose Dietary Supplement Use. Clinical Pharmacology \& Therapeutics, 71, 421-432. https://doi.org/10.1067/mcp.2002.124523

[4] Vukovich, M.D., Schoorman, R., Heilman, C., et al. (2005) Caffeine-Herbal Ephedra Combination Increases Resting Energy Expenditure, Heart Rate and Blood Pressure. Clinical and Experimental Pharmacology and Physiology, 32, 47-53. https://doi.org/10.1111/j.1440-1681.2005.04152.x

[5] Stohs, S.J., Shara, M. and Ray, S.D. (2020) p-Synephrine, Ephedrine, p-Octopamine and $m$-Synephrine: Comparative Mechanistic, Physiological and Pharmacological Properties. Phytotherapy Research, early view.

[6] Guo, Y. (2013) Basic Research on the Composition Rules of Herba Ephedra Couplet Medicines-Couplet Medicines of Herba Ephedra-Semen Amarum(II). Master's Thesis, Southern Medical University, Guangzhou.

[7] Chang, C.W., Hsu, S.Y., Huang, G.Q., et al. (2017) Ephedra Alkaloid Contents of Chinese Herbal Formulae Sold in Taiwan. Drug Testing and Analysis, 10, 350-356. https://doi.org/10.1002/dta.2209

[8] Eccles, R. (2007) Substitution of Phenylephrine for Pseudoephedrine as a Nasal Decongeststant. An Illogical Way to Control Methamphetamine Abuse. British Journal of Clinical Pharmacology, 63, 10-14. https://doi.org/10.1111/j.1365-2125.2006.02833.x

[9] Klimek, L., Schumacher, H., Schütt, T., et al. (2017) Factors Associated with Efficacy of an Ibuprofen/Pseudoephedrine Combination Drug in Pharmacy Customers with Common Cold Symptoms. The International Journal of Clinical Practice, 71, e12907. https://doi.org/10.1111/ijcp.12907

[10] Nassiri-Asl, M. (2015) Pharmacological Effects of Glycyrrhiza spp. and Its Bioactive Constituents: Update and Review. Phytotherapy Research, 29, 1868-1886. https://doi.org/10.1002/ptr.5487

[11] Asl, M.N. and Hosseinzadeh, H. (2008) Review of Pharmacological Effects of Glycyrrhiza sp. and Its Bioactive Compounds. Phytotherapy Research, 22, 709-724. https://doi.org/10.1002/ptr.2362

[12] Pastorino, G., Cornara, L., Soares, S., et al. (2018) Liquorice (Glycyrrhiza glabra): A Phytochemical and Pharmacological Review. Phytotherapy Research, 32, 2323-2339. https://doi.org/10.1002/ptr.6178

[13] Laconi, S., Madeddu, M.A. and Pompei, R. (2014) Autophagy Activation and Antiviral Activity by a Licorice Triterpene. Phytotherapy Research, 28, 1890-1892. https://doi.org/10.1002/ptr.5189

[14] Okuyama, T. (2009) Isoliquiritigenin, a Flavonoid from Licorice, Reduces Prostaglandin $\mathrm{E}_{2}$ and Nitric Oxide, Causes Apoptosis, and Suppresses Aberrant Crypt Foci Development. Cancer Science, 95, 448-453. https://doi.org/10.1111/j.1349-7006.2004.tb03230.x

[15] Zhang, E. X., Yin, S. T., Zhao, S. et al. (2020) Protective Effects of Glycycoumarin 
on Liver Diseases. Phytotherapy Research, 34, 1191-1197.

[16] Chigurupati, H., Auddy, B., Biyani, M., et al. (2016) Hepatoprotective Effects of a Proprietary Glycyrrhizin Product during Alcohol Consumption: A Randomized, Double-Blind, Placebo-Controlled, Crossover Study. Phytotherapy Research, 30, 1943-1953. https://doi.org/10.1002/ptr.5699

[17] Yu, J., Jiang, Y.-S., Jiang, Y., et al. (2014) Targeted Metabolomic Study Indicating Glycyrrhizin's Protection against Acetaminophen-induced Liver Damage through Reversing Fatty Acid Metabolism. Phytotherapy Research, 28, 933-936. https://doi.org/10.1002/ptr.5072

[18] Bielenberg, J. (2008) Antiviral Effects of Glycyrrhiza Species. Phytotherapy Research, 22, 141-148. https://doi.org/10.1002/ptr.2295

[19] Fiore, C., Eisenhut, M., Krausse, R., et al. (2008) Antiviral Effects of Glycyrrhiza Species. Phytotherapy Research, 22, 141-148. https://doi.org/10.1002/ptr.2295

[20] Kang, D.-G., Sohn, E.-J., Mun, Y.-J., et al. (2003) Glycyrrhizin Ameliorates Renal Function Defects in the Early-Phase of Ischemia-Induced Acute Renal Failure. Phytotherapy Research, 17, 947-951. https://doi.org/10.1002/ptr.1270

[21] Gaur, R., Gupta, V.K., Singh, P., et al. (2016) Drug Resistance Reversal Potential of Isoliquiritigenin and Liquiritigenin Isolated from Glycyrrhiza glabra against Methicillin-Resistant Staphylococcus aureus (MRSA). Phytotherapy Research, 30, 1708-1715. https://doi.org/10.1002/ptr.5677

[22] Zhou, Y.X., Li, M., Tang, Z.S., et al. (2012) An Study on Gypusm Compounds and Their Antipyretic Function and Anti-Inflammatory Mechanisms. Journal of Shaanxi College of Traditional Chinese Medicine, 35, 74-76.

[23] Liu, J., Zhang, Q., Li, R.L., et al. (2019) The Traditional Uses, Phytochemistry, Pharmacology and Toxicology of Cinnamomi ramulus. A Review. Journal of Pharmacy \& Pharmacology, 72, 319-342. https://doi.org/10.1111/jphp.13189

[24] Kumar, S., Kumari, R. and Mishra, S. (2019) Pharmacological Properties and Their Medicinal Uses of Cinnamomum: A Review. Journal of Pharmacy \& Pharmacology, 71, 1735-1761. https://doi.org/10.1111/jphp.13173

[25] Xu, F., Li, Z., Zheng, J., et al. (2013) The Inhibitory Effects of the Bioactive Components Isolated from Scutellaria baicalensis on the Cellular Uptake Mediated by the Essential Solute Carrier Transporters. Journal of Pharmaceutical Sciences, 102, 4205-4211. https://doi.org/10.1002/jps.23727

[26] Zhang, L.L., Xu, W., Xu, Y.L., et al. (2017) Therapeutic Potential of Rhizoma Alismatis: A Review on Ethnomedicinal Application, Phytochemistry, Pharmacology, and Toxicology. Annals of the New York Academy of Sciences, 1401, 90-101. https://doi.org/10.1111/nyas.13381

[27] Miao, H., Zhang, L., Chen, D.Q., et al. (2017) Urinary Biomarker and Treatment Mechanism of Rhizoma alismatis on Hyperlipidemia. Biomedical Chromatography, 31, e3829. https://doi.org/10.1002/bmc.3829

[28] Ho, C., Gao, Y., Zheng, D., et al. (2019) Alisol A Attenuates High-Fat-Diet-Induced Obesity and Metabolic Disorders via the AMPK/ACC/SREBP-1c Pathway. Journal of Cellular and Molecular Medicine, 23, 5108-5118. https://doi.org/10.1111/jcmm.14380

[29] Li, H.-M., Chen, X.-J., Luo, D., et al. (2017) Protostane-Type Triterpenoids from Alisma orientale. Chemistry \& Biodiversity, 14, e1700452. https://doi.org/10.1002/cbdv.201700452

[30] Liu, Y.-Y. and Guo, S.-X. (2009) Nutritional Factors Determining Sclerotial Forma- 
tion of Polyporus umbellatus. Letters in Applied Microbiology, 49, 283-288. https://doi.org/10.1111/j.1472-765X.2009.02656.x

[31] Chen, X.-M., Tian, L.-X. and Guo, S.-X. (2017) Research Progress on Chemical Constituents and Pharmacological Effects of Sclerotia of Polyporus umbellatus (Polyporaceae, Basidiomycota). Mycosystema, 36, 35-47.

[32] Li, Y.H. (2017) Effect of Polyporus polysaccharide on Immune Function and Antioxidant Capacity in Mice. Master's Thesis, Shaanxi Normal University, Xi'an.

[33] Li, S.M. (2015) Pharmacokinetic Study of the Diuretic Mechanism and Its Active Components of Polyporus umbellatus in Rats. Doctor's Thesis, Guangzhou University of Chinese Medicine, Guangzhou.

[34] Liu, R.J., Zhang, Y., Tian, W., et al. (2019) Study on the Hygroscopic Effect of Polyporus umbellata and Its Pharmacological Activity. Edible Fungi of China, 1, 68-71.

[35] Wang, K.-T., Chen, L.-G., Wu, C.-H., et al. (2010) Gastroprotective Activity of Atractylenolide III from Atractylodes ovata on Ethanol-Induced Gastric Ulcer in Vitro and in Vivo. Journal of Pharmacy and Pharmacology, 62, 381-388. https://doi.org/10.1211/jpp.62.03.0014

[36] Li, C.-Q., He, L.-C. and Jin, J.-Q. (2007) Atractylenolide I and Atractylenolide III Inhibit Lipopolysaccharide-Induced TNF- $\alpha$ and NO Production in Macrophages. Phytotherapy Research, 21, 347-353. https://doi.org/10.1002/ptr.2040

[37] Fu, X.-Q., Chou, G.-X., Kwan, H.Y., et al. (2014) Inhibition of STAT3 Signalling Contributes to the Antimelanoma Action of Atractylenolide II. Experimental Dermatology, 23, 855-857. https://doi.org/10.1111/exd.12527

[38] Gao, Q., Ji, Z.-H., Yang, Y., et al. (2012) Neuroprotective Effect of Rhizoma Atractylodis Macrocephalae against Excitotoxicity-Induced Apoptosis in Cultured Cerebral Cortical Neurons. Phytotherapy Research, 26, 557-561. https://doi.org/10.1002/ptr.3595

[39] Jeong, J.-W., Lee, W.S., Go, S.-I., et al. (2015) Pachymic Acid Induces Apoptosis of EJ Bladder Cancer Cells by DR5 Up-Regulation, ROS Generation, Modulation of Bcl-2 and IAP Family Members. Phytotherapy Research, 29, 1516-1524. https://doi.org/10.1002/ptr.5402

[40] Fuchs, S.M., Heinemann, C., Schliemann-Willers, S., et al. (2006) Assessment of Anti-Inflammatory Activity of Poria cocos in Sodium Lauryl Sulphate-Induced Irritant Contact Dermatitis. Skin Research and Technology, 12, 223-227.

https://doi.org/10.1111/j.0909-752X.2006.00168.x

[41] Mizushina, Y., Akihisa, T., Ukiya, M., et al. (2004) A Novel DNA Topoisomerase Inhibitor: Dehydroebriconic Acid, One of the Lanostane-Type Triterpene Acids from Poria cocos. Cancer Science, 95, 354-360. https://doi.org/10.1111/j.1349-7006.2004.tb03215.x

[42] Li, X., He, Y., Zeng, P., et al. (2019) Molecular Basis for Poria cocos Mushroom Polysaccharide Used as an Antitumour Drug in China. Journal of Cellular and Molecular Medicine, 23, 4-20. https://doi.org/10.1111/jcmm.13564

[43] Wu, K., Guo, C., Yang, B., et al. (2019) Antihepatotoxic Benefits of Poria cocos Polysaccharides on Acetaminophen-Lesioned Livers in Vivo and in Vitro. Journal of Cellular Biochemistry, 120, 7482-7488. https://doi.org/10.1002/jcb.28022

[44] Su, G.Y., Yang, J.Y., Wang, F., et al. (2014) Xiaochaihutang Prevents Depressive-Like Behaviour in Rodents by Enhancing the Serotonergic System. Journal of Pharmacy \& Pharmacology, 66, 823-834. https://doi.org/10.1111/jphp.12201 
[45] Cheng, P.W., Ng, L.T., Chiang, L.C., et al. (2010) Antiviral Effects of Saikosaponins on Human Coronavirus 229E in Vitro. Clinical \& Experimental Pharmacology \& Physiology, 33, 612-616. https://doi.org/10.1111/j.1440-1681.2006.04415.x

[46] Zhao, T., Tang, H., Xie, L., et al. (2019) Scutellaria baicalensis Georgi. (Lamiaceae): A Review of Its Traditional Uses, Botany, Phytochemistry, Pharmacology and Toxicology. Journal of Pharmacy and Pharmacology, 71, 1353-1369. https://doi.org/10.1111/jphp.13129

[47] Nan, J.X., Park, E.J., Kim, Y.C., et al. (2002) Scutellaria baicalensis Inhibits Liver Fibrosis Induced by Bile Duct Ligation or Carbon Tetrachloride in Rats. Journal of Pharmacy \& Pharmacology, 54, 555-563. https://doi.org/10.1211/0022357021778673

[48] Heo, H.J., Lee, H.J., Kim, Y.S., et al. (2007) Effects of Baicalin and Wogonin on Mucin Release from Cultured Airway Epithelial Cells. Phytotherapy Research, 21, 1130-1134. https://doi.org/10.1002/ptr.2222

[49] Yao, J., Pan, D., Zhao, Y., et al. (2014) Wogonin Prevents Lipopolysaccharide-Induced Acute Lung Injury and Inflammation in Mice via Peroxisome Proliferator-Activated Receptor Gamma-Mediated Attenuation of the Nuclear Factor-kappaB Pathway. Immunology, 143, 241-257. https://doi.org/10.1111/imm.12305

[50] Mamadalieva, D.P.N.Z., Herrmann, F., El-Readi, M.Z., et al. (2011) Flavonoids in Scutellaria immaculata and S. ramosissima (Lamiaceae) and Their Biological Activity. Journal of Pharmacy \& Pharmacology, 63, 1346-1357. https://doi.org/10.1111/j.2042-7158.2011.01336.x

[51] Wei, C.Y., Sun, H.L., Yang, M.L., et al. (2017) Protective Effect of Wogonin on Endotoxin-Induced Acute Lung Injury via Reduction of p38 MAPK and JNK Phosphorylation. Environmental Toxicology, 32, 397-403. https://doi.org/10.1002/tox.22243

[52] Yune, T.Y., Lee, J.Y., Cui, C.M., et al. (2009) Neuroprotective Effect of Scutellaria baicalensis on Spinal Cord Injury in Rats. Journal of Neurochemistry, 110, 1276-1287. https://doi.org/10.1111/j.1471-4159.2009.06214.x

[53] Liu, L.-Y., Wei, E.-Q., Zhao, Y.-M., et al. (2005) Protective Effects of Baicalin on Oxygen/Glucose Deprivation- and NMDA-Induced Injuries in Rat Hippocampal Slices. Journal of Pharmacy \& Pharmacology, 57, 1019-1025. https://doi.org/10.1211/0022357056622

[54] Mehendale, S., Han, A., Wang, C.Z., et al. (2007) Scutellaria baicalensis and a Constituent Flavonoid, Baicalein, Attenuate Ritonavir-Induced Gastrointestinal Side-Effects. Journal of Pharmacy \& Pharmacology, 59, 1567-1572. https://doi.org/10.1211/jpp.59.11.0015

[55] Bochořáková, H., Paulová, H., Slanina, J., et al. (2003) Main Flavonoids in the Root of Scutellaria baicalensis Cultivated in Europe and Their Comparative Antiradical Properties. Phytotherapy Research, 17, 640-644. https://doi.org/10.1002/ptr.1216

[56] Kimura, Y., Yokoi, K., Matsushita, N., et al. (1997) Effects of Flavonoids Isolated from Scutellariae Radix on the Production of Tissue-Type Plasminogen Activator and Plasminogen Activator Inhibitor-1 Induced by Thrombin and Thrombin Receptor Agonist Peptide in Cultured Human Umbilical Vein Endothelial Cells. Journal of Pharmacy \& Pharmacology, 49, 816-822. https://doi.org/10.1111/j.2042-7158.1997.tb06119.x

[57] Króliczewska, B., Miśta, D., Zawadzki, W., et al. (2011) Effects of a Skullcap Root Supplement on Haematology, Serum Parameters and Antioxidant Enzymes in Rabbits on a High-Cholesterol Diet. Journal of Animal Physiology \& Animal Nutrition, 95, 114-124. https://doi.org/10.1111/j.1439-0396.2010.01033.x 
[58] Lee, J.H. and Lee, S.-R. (2012) The Effect of Baicalein on Hippocampal Neuronal Damage and Metalloproteinase Activity Following Transient Global Cerebral Ischaemia. Phytotherapy Research, 26, 1614-1619. https://doi.org/10.1002/ptr.4644

[59] Li, Q., Yu, Z.J., Xiao, D.D., et al. (2020) Baicalein Inhibits Mitochondrial Apoptosis Induced by Oxidative Stress in Cardiomyocytes by Stabilizing MARCH5 Expression. Journal of Cellular and Molecular Medicine, 24, 2040-2051. https://doi.org/10.1111/jcmm.14903

[60] Zong, J., Zhang, D.P., Zhou, H., et al. (2013) Baicalein Protects against Cardiac Hypertrophy through Blocking MEK-ERK1/2 Signaling. Journal of Cellular Biochemistry, 114, 1058-1065. https://doi.org/10.1002/jcb.24445

[61] Jiang, W.B., Zhao, W., Chen, H., et al. (2017) Baicalin Protects H9c2 Cardiomyocytes against Hypoxia/Reoxygenation-Induced Apoptosis and Oxidative Stress through Activation of Mitochondrial Aldehyde Dehydrogenase 2. Clinical and Experimental Pharmacology and Physiology, 45, 303-311. https://doi.org/10.1111/1440-1681.12876

[62] Zhang, X. and Yu, J. (2005) Baicalin Attenuates Gentamicin-Induced Cochlear Hair Cell Ototoxicity. Journal of Applied Toxicology, 57, 1581-1590.

[63] Kim, D.H., Cho, K.H., Sang, K.M., et al. (2006) Cytoprotective mechanism of Baicalin against Endothelial Cell Damage by Peroxynitrite. Journal of Pharmacy \& Pharmacology, 57, 1581-1590. https://doi.org/10.1211/jpp.57.12.0008

[64] Tsai, T.H., Liu, S.C., Tsai, P.L., et al. (2002) The Effects of the Cyclosporin A, a P-Glycoprotein Inhibitor, on the Pharmacokinetics of Baicalein in the Rat: A Microdialysis Study. British Journal of Pharmacology, 137, 1314-1320.

https://doi.org/10.1038/sj.bjp.0704959

[65] Chen, Y. and Zhu, J. (2013) Anti-HBV Effect of Individual Traditional Chinese Herbal Medicine in Vitro and in Vivo: An Analytic Review. Journal of Viral Hepatitis, 20, 445-452. https://doi.org/10.1111/jvh.12112

[66] Van Dien, M., Takahashi, K., Mu, M.M., et al. (2001) Protective Effect of Wogonin on Endotoxin-Induced Lethal Shock in D-Galactosamine-Sensitized Mice. Microbiology \& Immunology, 45, 751-756. https://doi.org/10.1111/j.1348-0421.2001.tb01311.x

[67] Zuo, J., Mou, J. and Hu, X. (2019) Research Progress in the Chemical Constituents and Modern Pharmacological Effects of Pinellia ternata. Journal of Liaoning University of TCM, 21, 26-29.

[68] Zhang, H., Yan, G.-H., Lai, X., et al. (2019) Study on the Antitussive and Expectorant Effects of Pinelliae Rhizoma Praeparatum Cum Zingibere et Alumine. Journal of Jiangxi University of TCM, 31, 80-82.

[69] Li, Y.-N., Zhang, G.-G., Mao, D.-S., et al. (2007) Chemical Constituents of Belamcanda chinensis (L.) DC. Central South Pharmacy, 5, 222-224.

[70] Li, G.X. (2008) Study on the Therapeutic Basis of traditional Chinese Medicinal Preparation Belamcanda chinensis about Bacteriostasis, Antiinflammation, Stopping Cough Effect and Pharmacolinetics of Related Elements. Doctor's Thesis, Liaoning University of Traditional Chinese Medicine, Shenyang.

[71] Xu, L.-J., Li, C., Zhang, M., et al. (2011) Effect of the Ethyl acetate Extract of Farfarae flos on Inflammatory Factors. Journal of China Pharmaceutical University, 42, 64-67.

[72] Huang, X., Cai, C.H., Feng, X.H., et al. (2019) Comparison of Expectorant Effect Between Pinellia rhizoma and Processed Pinellia rhizoma on Rats with Syndrome of 
Cold-Damp Amassing in Lung. Jilin Journal of Traditional Chinese Medicine, 39, 793-796.

[73] Shi, X.L., Niu, L.Y., Zhao, L.N., et al. (2018) The Antiallergic Activity of Flavonoids Extracted from Citri reticulatae Pericarpium. Journal of Food Processing and Preservation, 42, e13588. https://doi.org/10.1111/jfpp.13588

[74] Shin, S. and Kang, C.A. (2003) Antifungal Activity of the Essential Oil of Agastache rugosa Kuntze and Its Synergism with Ketoconazole. Letters in Applied Microbiology, 36, 111-115. https://doi.org/10.1046/j.1472-765X.2003.01271.x

[75] Zhang, J.-J., Dong, X., Cao, Y.-Y., et al. (2020) Clinical Characteristics of $140 \mathrm{~Pa}-$ tients Infected with SARS-CoV-2 in Wuhan, China. Allergy, 75, 1730-1741. https://doi.org/10.1111/all.14238

[76] Wang, S., Tang, Q., Qian, W., et al. (2012) Meta-Analysis of Clinical Trials on Traditional Chinese Herbal Medicine for Treatment of Persistent Allergic Rhinitis. Allergy, 67, 583-592. https://doi.org/10.1111/j.1398-9995.2012.02806.x 